\title{
Columban simulation project: Quando computadores foram substituídos por pombos
}

\section{Columban simulation project: When pigeons replaced computers \\ Columban simulation project: Cuando las computadoras fueron reemplazadas por palomas}

\author{
Hernando Borges Neves Filho ${ }^{1}$
}

Resumo: Durante a década de 1980, Skinner e colegas publicaram uma série de pesquisas empíricas que trataram de temas como comunicação simbólica, uso de ferramentas, "Insight", auto-reconhecimento e outros temas típicos de pesquisas de viés cognitivo. Tais pesquisas estavam vinculadas ao chamado Columban Simulation Project, que foi um projeto desenvolvido nos últimos anos de Skinner em Harvard, e tinha como objetivo central recriar em pombos fenômenos tradicionalmente tratados como complexos, observados em chimpanzés e humanos. Adicionalmente, o projeto também tinha o intuito de debater o papel de simulações de comportamento, no caso, comparando simulações de comportamentos em pombos com simulações de computador. O presente ensaio faz um apanhado de todos os principais trabalhos do Columban Simulation Project, discutindo e relacionando seus experimentos com pesquisas atuais, ao mesmo tempo em que trata também de algumas de suas críticas e legados. Conclui-se que o projeto chamou razoável atenção da comunidade científica, dentro e fora da Análise do Comportamento, assim como consolidou uma linha de pesquisa ativa sobre as origens operantes de comportamentos tradicionalmente chamados de "Insight", e ao mesmo tempo serviu como uma ponte de aproximação da Análise do Comportamento com algumas vertentes atuais das ciências cognitivas e desenvolvimento de inteligências artificiais.

Palavras-chave: metodologia de pesquisa, simulações, comportamento complexo, cognição, história comportamental 
Abstract: During the decade of 1980, Skinner and colleagues published a series of empirical research regarding themes such as symbolic communication, tool use, insight, self-awareness, and other popular themes of cognitive research. These papers were part of the so called Columban Simulation Project, an endeavor took by Skinner in his last years at Harvard, that aimed to recreate complex phenomena, easily observed in chimpanzees and humans, in pigeons. The project also had the objective to discuss the role of simulation research in Psychology experiments. The present essay offers a comprehensive description and discussion, in Portuguese, of all major papers related to the project. Implications of these papers to modern research in behavior analysis, cognitive science and computer science are discussed, among examples of some critics aimed to the project and also its lasting legacy to psychological research. It is concluded that the project had a reasonable impact in the scientific community at large, established a line of investigation of the operant determinants of problem solving performances, and that it also brought together discussions and data from research in behavior analysis, cognitive science and artificial intelligence.

Keywords: methodology, simulations, complex behavior, cognition, behavioral history

Resumen: Durante la década de 1980, Skinner y colegas publicaron una serie de investigaciones empíricas que trataron temas como comunicación simbólica, uso de herramientas, «Insight», auto-reconocimiento y otros temas típicos de investigaciones de sesgo cognitivo. Tales investigaciones estaban vinculadas al llamado Columban Simulation Project, que fue un proyecto desarrollado en los últimos años de Skinner en Harvard, y tenía como objetivo central recrear en palomas fenómenos tradicionalmente tratados como complejos, observados en chimpancés y humanos. Además, el proyecto también tenía el intuito de debatir el papel de simulaciones de comportamiento, en el caso, comparando simulaciones de comportamientos en palomas con simulaciones de computadora. El presente ensayo recoge todos los principales trabajos del Columban Simulation Project, discutiendo y relacionando sus experimentos con investigaciones actuales, al mismo tiempo que trata también de algunas de sus críticas y legados. Se concluye que el proyecto llamó razonable atención de la comunidad científica, dentro y fuera del Análisis del Comportamiento, así como consolidó una línea de investigación activa sobre los orígenes operantes de comportamientos tradicionalmente llamados «Insight», y al mismo tiempo sirvió como una puente de aproximación del Análisis del Comportamiento con algunas vertientes actuales de las ciencias cognitivas y inteligencias artificiales.

Palabras-clave: metodología de investigación, simulaciones, comportamiento complejo, cognición, historia conductual 
Na década de 1980, Skinner assinou em conjunto com colegas e alunos uma série de experimentos com pombos (Columba livia), que tinha por objetivo simular comportamentos complexos a partir de variados treinos operantes (Epstein, 1981; 1986; 1996; 2015b). O principal porta voz do projeto foi Robert Epstein, e no total, os experimentos do projeto renderam a publicação de oito artigos com dados empíricos, um vídeo documentário (Baxley, 1982), e um livro compilando alguns dos artigos e outras publicações relacionadas ao projeto (Epstein, 1996).

Epstein (1981) indica que um dos destaques da empreitada foi levar a Análise do Comportamento à temas tradicionalmente investigados por psicólogos de viés cognitivo, e nesse sentido, contribuir com dados no debate sobre estes temas. O projeto se caracterizava por uma abordagem na qual a Análise do Comportamento tanto dialoga com a então popular psicologia cognitiva (em geral em tom de crítica), ao mesmo tempo em que mostra o poder e eficácia de procedimentos operantes em descrever e modular os chamados processos cognitivos em voga.

Diante disto, o presente ensaio tem por objetivo fazer uma breve descrição em português dos principais trabalhos do projeto, originalmente publicados em inglês, situando-os no contexto da época no qual se inserem. Adicionalmente, é feito um apanhado do legado do projeto, quais foram suas principais críticas, e quais suas influências em pesquisas atuais que tratam dos temas abordados pelo projeto. Os trabalhos publicados descritos a seguir foram selecionados de acordo com sua pertinência ao projeto, como relatada por seus próprios autores, e compilada por Epstein (1996).

\section{Sobre simulações, pombos e computadores}

$\mathrm{O}$ artigo inaugural do projeto, "Symbolic communication between two pigeons (Columba livia domestica)" (Epstein, Lanza \& Skinner, 1980), não faz menção ao projeto e é uma descrição isolada de um experimento com os hoje famosos pombos Jack e Jill (mais detalhes sobre esse experimento adiante). Apenas em um artigo publicado um ano depois (Epstein, 1981) o projeto é detalhado, em meio a uma redescrição do experimento com Jack e Jill, aliada à descrições e dados parciais de alguns dos experimentos posteriormente publicados em completo.

Segundo Epstein (1981), a ideia do projeto começou a tomar forma em 1979, quando os primeiros experimentos foram delineados e quando o projeto foi batizado pelo próprio Skinner. Inicialmente o projeto seria chamado de "Pigeon simulation project", Skinner então sugeriu trocar "pigeon" por "Columban", por ser o nome científico da espécie (Columba livia), e também por ser parecido com "computer" (Epstein, 1981, p.48), já antecipando um dos objetivos do projeto.

Dois foram os motivos que levaram a criação do projeto: (1) criar referências empíricas para comentar abordagens "não behavioristas" sobre comportamento humano, e (2) identificar as variáveis que controlam comportamentos ditos complexos (Epstein, 1981). Partindo disto, Epstein (1981) compara estudar comportamentos ditos complexos em pombos com simulações de comportamento em computador.

Epstein (1981) aponta algumas limitações das simulações de comportamento em computador. Uma delas se dá na redundância da programação, na medida em que diferentes programas podem gerar um mesmo processo, não há como definir um programa como o inequívoco processo de uma determinada simulação. Uma outra limitação seria de que não há nenhuma sobreposição da composição de um computador, feito de silício, de acordo com um design específico (em geral voltado à performance), com a composição de um organismo, moldado de forma não direcionada por milhões de anos de seleção natural. Partindo destas críticas, são elencados os motivos que levam o autor a considerar como mais vantajosa a simulação de comportamentos ditos complexos em pombos, em vez de simulações em máquinas.

A primeira vantagem é que pombos são organismos, e neste sentido, a fisiologia de humanos e outros animais se aproxima mais a de pombos do que de computadores, o que permite maior generalização dos dados. A segunda vantagem é que se uma determinada história de reforço produz um desempenho típico de instâncias relacionadas a 
processos cognitivos e comportamentos complexos, há aí então indícios de que variáveis históricas produzem este desempenho, o que leva a possibilidade de previsão e controle deste fenômeno (Epstein, 1981). Se um mesmo processo é observado tanto em chimpanzés como pombos, dois organismos com histórias filogenéticas bastante distintas, é possível atribuir papel fundamental às contingências, a história de vida que permite aquele desempenho, sem necessariamente invocar diferenças qualitativas entre espécies com maior ou menor capacidade cognitiva ou grau de encefalização.

Epstein (1986) ressalta que por mais que estes repertórios sejam então passíveis de serem produzidos em pombos, estes continuam sendo simulações, na medida em que são comparados com instâncias similares em outras espécies, já que as variáveis de controle são distintas para cada espécie e para cada situação. Um chimpanzé que se reconhece no espelho possivelmente está se comportando de acordo com contingências distintas das dos pombos que também se reconhecem no espelho. De qualquer maneira, ao simular estes comportamentos em diferentes organismos, é possível traçar um tipo de história que produz estes comportamentos, algo impossível de se obter em simulações de computador da época (Epstein, 1981).

Partindo disto, os primeiros experimentos publicados contaram com o hoje famoso par de pombos que, com o devido treino, se engajaram em análogos de comportamento simbólico.

Um diálogo entre pombos: comunicação simbólica, produção espontânea de "lembretes" e o reforço da mentira

Epstein, Lanza e Skinner (1980) treinaram repertórios distintos em dois pombos, Jack e Jill. Em uma caixa acoplada, separada por uma parede translúcida que permitia o pombo ter acesso visual a seu par, a seguinte performance foi observada na situação de teste. Jack (do lado esquerdo da caixa) iniciava a sessão bicando uma placa com os dizeres "WHAT COLOR?" ("qual cor?"). Com a bicada, o painel com os dizeres "WHAT COLOR?" se acendia, e Jill, do outro lado da caixa (lado direito) coloca sua cabeça em um orifício coberto por uma cortina, e observa uma dentre três possíveis cores apresentadas ali (vermelho, verde ou amarelo). Após observar a cor, Jill então vai até um painel com três discos, cada um com uma letra, e cada letra correspondendo a primeira letra do nome de uma das três possíveis cores em inglês ("R", "G" e "Y"). Jill bica o disco correspondente à cor apresentada no orifício, que acende ao ser bicado. Jack, pressiona então um outro disco, com os dizeres "THANK YOU" no seu lado da câmara experimental e isso libera o comedouro com alimento no lado direito da câmara. Jill procede então ao comedouro, e Jack bica em um painel do seu lado da câmara a cor correspondente a letra que Jill pressionou (e que por sua vez correspondia a cor que ela observou no orifício). As cores eram apresentadas no orifício de forma pseudorrandômica a cada tentativa (Figura 1). Todo este intrincado responder coordenado entre os dois pombos foi resultado de um treino específico, uma modelagem, dada a cada um deles.

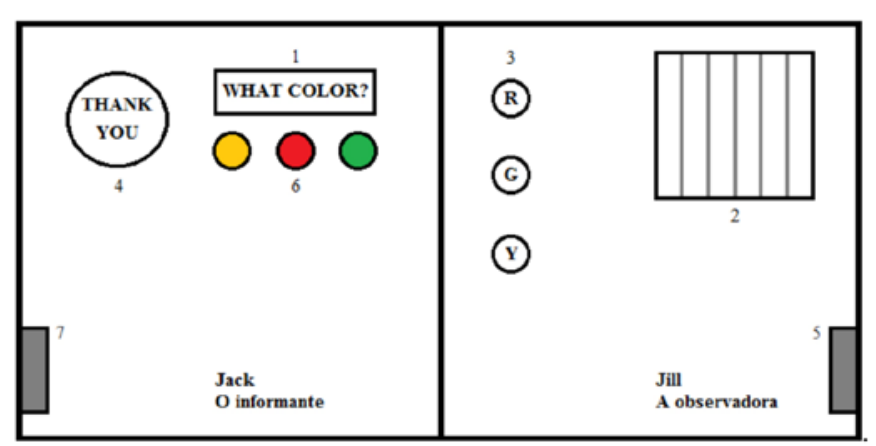

Figura 1. Diagrama esquemático da câmara acoplada utilizada nos experimentos com os pombos Jack e Jill. Na porção esquerda da figura consta a câmara com os estímulos e operandos manipulados por Jack, o "informante. Na porção direita, constam os estímulos e operandos disponíveis a Jill, a "observadora". Os números indicam a ordem de interação observada com os estímulos e operandos durante a comunicação simbólica entre Jack e Jill. (1) é a resposta que inicia a comunicação, a bicada no painel "WHAT COLOR?", que liga uma de três possíveis cores (vermelho, verde ou amarelo) em (2), que é um orifício coberto por uma cortina. Ao observar a cor ligada em (2), Jill então deve bicar na letra correspondente àquela cor no painel vertical de três discos (3). Ao observar a resposta (3) de Jill, Jack então bica o botão "THANK YOU" (4), que aciona o comedouro de Jill (5) e liga os três discos horizontais em sua porção da câmara (6). Ao bicar no disco horizontal com a cor correspondente à letra inicial desta cor, acionada por Jill, Jack aciona o seu comedouro (7) e encerra o episódio de comunicação. Todos estes repertórios foram modelados passo a passo, entretanto a interação entre os dois pombos nunca foi diretamente treinada. 
Jack aprendeu os repertórios de "observador", e Jill de "informante". O treino durou cerca de cinco semanas. Jack aprendeu a escolher um disco com uma cor correspondente a letra inicial do nome da cor em inglês (por exemplo, se o disco com a letra " $R$ " acendesse, Jack deveria bicar o disco vermelho). Depois, Jack foi treinado a primeiro pressionar o disco com os dizeres "WHAT COLOR?" para assim ter acesso ao disco com as cores, e também a pressionar o disco "THANK YOU” após escolher a cor, de acordo com a letra apresentada. Jill aprendeu a escolher uma letra de acordo com a cor apresentada. A cor era apresentada em um orifício que impedia que o pombo do outro lado da caixa tivesse acesso visual a ela, de modo que só Jill tinha acesso a essa cor. Quando ambos os pombos foram colocados na caixa, cada um com seu repertório, foi então observado o desempenho coordenado, descrito anteriormente.

Em uma continuação deste experimento (Epstein \& Skinner, 1981), Jack e Jill aprenderam os repertórios de seus parceiros e foram colocados sozinhos na câmara experimental, desta vez sem a divisória transparente. $\mathrm{O}$ seguinte padrão comportamental foi observado: Jack observava a cor apresentada no orifício, e imediatamente bicava a letra correspondente a cor. Após isso Jack se aproximou do outro painel de discos e bicou a cor correspondente à letra que ele havia bicado antes (que por sua vez era correspondente a cor observada no orifício). Este padrão se manteve em todas as tentativas subsequentes, e Jill apresentou performance similar. Epstein e Skinner (1981) argumentam que os pombos estavam usando o painel com a letra correspondente a cor apresentada no orifício (do lado direito) como um "lembrete" ("memoranda"), que serviria de "dica" na hora de escolher o painel mais afastado (o painel do lado esquerdo, com as cores).

Em um terceiro experimento com este procedimento, ainda com os pombos Jack e Jill, Lanza, Starr e Skinner (1982) observaram a emergência de um comportamento funcionalmente similar a uma "mentira". Neste experimento, a magnitude do reforço foi alterada para cada cor relatada pelo informante, sendo a cor vermelha a com maior magnitude das três. Assim, sempre que o informante relatava a cor vermelha, o comedouro era acionado por mais tempo, o que permitia aos animais obter mais alimento. Nessa contingência, observou-se que os pombos "erraram" em mais tentativas, em geral informando a cor vermelha ao seu par, mesmo quando essa não era a cor disponível no orifício disponível ao informante. Nestes casos, como a cor selecionada pelo observador era distinta da cor dada ao informante, já que o informante dava uma informação falsa, nenhuma consequência era disponibilizada. Ainda assim, os autores relatam que a predileção pelo vermelho, a "mentira" do informante, perdurou por quinze dias, até que as respostas de "mentira" fossem extintas.

Os três experimentos realizados com Jack e Jill (Epstein, Lanza \& Skinner, 1980; Epstein \& Skinner, 1981; Lanza, Starr \& Skinner, 1982) foram uma resposta a um experimento realizado por SavageRumbaugh, Rumbaugh e Boysen (1978) com chimpanzés (Pan troglodytes). Epstein (1986) argumenta que neste estudo pouca atenção foi dada ao efeito do treino dos comportamentos pré-requisito que levaram a observação da interação simbólica entre um par de chimpanzés, e tal postura suscitava discussões em torno da "inteligência" e outras antropomorfizações ligadas a supostas instâncias cognitivas relacionadas à linguagem. Neste cenário, os estudos com os pombos Jack e Jill oferecem argumentos alternativos e complementares, que dão visibilidade às contingências que levam a esse tipo de performance, ao mesmo tempo em que mostram que estas contingências são o suficiente, sem a necessidade de supor "inteligências" superiores ou inferiores para explicar a ocorrência do fenômeno.

\section{Pombos e espelhos: auto-reconhe- cimento e o encontro do "self"}

O segundo experimento do projeto tratou de outro tema de grande destaque na época. Gallup (1970) observou que chimpanzés (Pan troglodytes) demonstravam respostas de auto-conhecimento quando colocados em frente a um espelho. No procedimento, era pintado um pequeno círculo na testa dos animais, com tinta inodora, e após isso o animal tinha acesso a um espelho. Diversos animais então, diante de sua imagem, direcionavam suas mãos até a pinta em sua testa, e tratavam a imagem como uma reflexão de si. Partindo disso, 
o "teste de espelhos" tornou-se um procedimento utilizado para avaliar que animais reconheciam-se em espelho (cf. Galvão, Soares Filho, Neves Filho \& Nagahama, 2009), e disso derivava-se a noção de que animais possuíam ou não uma noção de eu, de "self" (entretanto, supunha-se que apenas animais que tratavam o espelho como seu reflexo possuíam esta noção). No estudo original, novamente pouca atenção foi dada às variáveis históricas responsáveis por esses comportamentos em relação ao espelho.

Epstein, Lanza e Skinner (1981) criaram então uma história de "uso de espelhos", em três pombos. Os autores treinaram dois repertórios distintos, em um período de dez dias. O primeiro repertório treinado foi bicar pontos azuis, afixados em locais visíveis no próprio corpo (asas, peito e abdômen). Ao bicar o ponto em seu corpo, o comedouro era acionado. Não havia nenhum espelho nesta etapa. Este repertório foi modelado até os pombos prontamente averiguarem seu próprio corpo em busca de pontos, bicando-os sempre que os encontrava. $\mathrm{O}$ segundo repertório foi treinado na presença de um espelho, e inicialmente pontos azuis foram apresentados em diferentes locais da parede da câmara experimental. Ao bicar estes pontos, idênticos aos usados no treino do primeiro repertório, os animais recebiam alimento. Após essa primeira etapa, os pontos foram então apresentados brevemente, $\mathrm{e}$ os pombos deveriam bicar o local onde o ponto foi apresentado (após a retirada do ponto). Em uma terceira etapa, o ponto foi apresentado em um local da câmara refletido no espelho (as apresentações foram feitas enquanto o pombo estava parado em frente ao espelho), e foram modeladas respostas de se virar, e bicar o local refletido no espelho (não foram reforçadas respostas de bicar o reflexo).

No teste, um ponto azul foi colocado no peito dos animais, coberto por um "colar" de papel branco. O colar foi colocado de tal forma que impedia o animal de ver o ponto, entretanto, o ponto ficava visível caso o pombo se posicionasse em frente ao espelho (Figura 2). Um controle inicial foi realizado com o ponto coberto com o colar, sem a presença do espelho, e nenhum pombo bicou o ponto escondido (também não foram observadas bicadas no colar, em um controle no qual o animal estava com o colar apenas, sem o espelho e sem o ponto escondido). Na presença do espelho, os três pombos prontamente inspecionaram o colar e bicaram o ponto escondido, repetidas vezes.

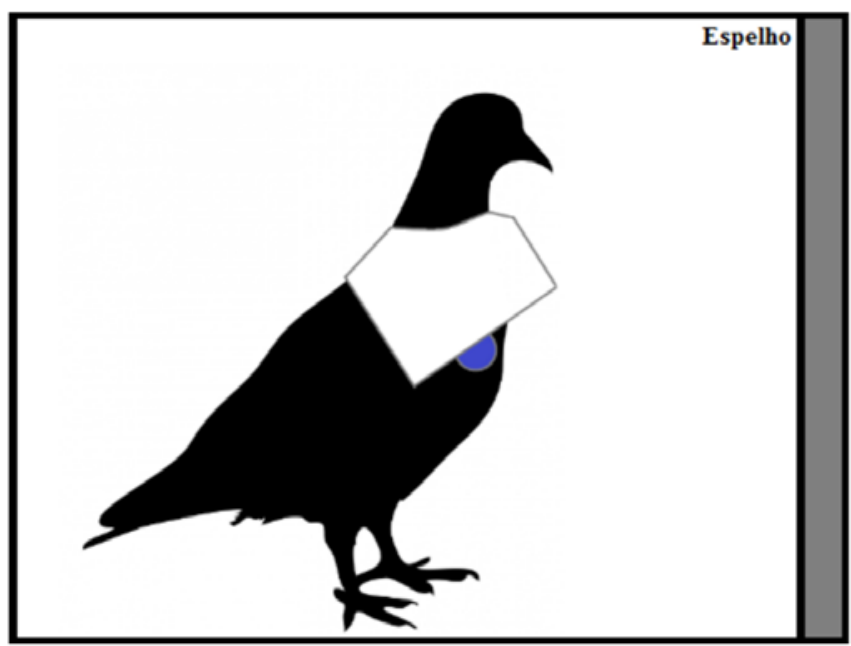

Figura 2. Diagrama esquemático do teste de espelho usado por Epstein, Lanza e Skinner (1981). Neste teste, os pombos vestiram um colar branco de tal forma que fosse impossível enxergar o ponto afixado no seu peitoral. Entretanto, o ponto ficava visível ao pombo em sua reflexão no espelho localizado a sua frente. Pombos com histórico com espelhos prontamente bicaram o ponto escondido, em alguns casos até deslocando o colar de local. Em uma situação idêntica, porém sem a presença do espelho, estes mesmos pombos não emitiram nenhuma bicada no ponto escondido pelo colar.

Epstein, Lanza e Skinner (1981) argumentam que o uso de espelhos depende de alguns repertórios pré-requisito. Bastando alguns repertórios, como os treinados, o uso do espelho é generalizado. Estes dados trouxeram novos argumentos ao uso de espelhos como testes de processos cognitivos, na medida em que não basta apenas apresentar um espelho ao animal. Para um dado mais completo, é necessário garantir ou medir quais repertórios de uso de espelho estes animais apresentam, e aí sim partir para análises de eventuais processos cognitivos envolvidos no uso de espelhos, caso este seja o interesse (Epstein, 1985a). Atualmente, boa parte dos estudos que utilizam de procedimentos com espelhos admitem o papel da aprendizagem no auto-reconhecimento, e utilizam disto para melhor abordar seus objetivos (e.g.Chang, Zhang, Poo \& Gong, 2017; Huttunen, Adams \& Platt, 2017) 


\section{Uso de ferramentas, resolução de problemas e ressurgência}

No artigo seguinte do projeto (Epstein \& Medalie, 1983), um pombo foi colocado em uma situação problema. Nesta situação, uma parede transparente impedia o acesso a uma placa localizada no piso da câmara experimental. Antes do teste, o pombo havia aprendido a bicar nessa placa, que liberava acesso a alimento. Com a inserção da parede transparente, o pombo enfrentava um problema: como alcançar a placa que libera alimento? A parede possuía um vão em sua parte inferior, que possibilitava o animal colocar seu pescoço, mas que não era grande o suficiente para permitir que o animal atravessasse de um lado para o outro da câmara experimental. Na situação problema, uma pequena caixa estava disponível, e após tentar alcançar a placa que liberava alimento esticando seu pescoço pelo vão da parede, o pombo foi em direção à caixa e começou a empurrá-la com bicadas, levando a caixa até o vão da parede a usando como uma "extensão" do seu bico, alcançando assim a placa que libera alimento. $\mathrm{O}$ uso espontâneo dessa caixa se deu em razão de um repertório treinado anteriormente.

Antes do teste, além de aprender a bicar a placa e receber alimento, o pombo aprendeu também a empurrar uma pequena caixa em direção a um alvo (um repertório complexo, que demorou seis meses para ser aprendido pelo pombo). Na situação de teste, com a placa fora do alcance e a caixa disponível, bicar a placa estava em extinção (já que era impossível de ocorrer), e isto provocou a ressurgência de empurrar (cf. Epstein, 1985c), que nesse caso, ocorreu de uma maneira nova. Empurrar foi treinado em direção a um alvo na parede, no teste ocorreu em direção a uma placa no piso. Este responder novo era um indicativo, segundo os autores, de que comportamentos estabelecidos em situações anteriores produzem novos, porém previsíveis, comportamentos em uma situação problema nova (Epstein \& Medalie, 1983). O seguinte trabalho do projeto explorou justamente este indicativo.

\section{"Insight" em pombos}

No começo do século XX, Wolfgang Köhler publicou um extenso estudo sobre a inteligência de chimpanzés (Pan troglodytes). Nesta obra, intitulada "Intelligenzprüfungen an Menschenaffen" (Köhler, 1916/1948), o autor relata um tipo de comportamento extraordinário que apenas alguns de seus sujeitos emitiam em determinadas situações problema, comportamento este que ficou conhecido como "Insight". Uma das performances relatadas por Köhler como um exemplo do chamado "Insight" envolvia uma situação problema na qual o animal necessitava empilhar caixas para alcançar uma banana. Em seu trabalho, Köhler deu pouca atenção à história de aprendizagem de seus chimpanzés, o que permitiu novamente interpretações antropomorfizadas e que menosprezavam o papel de experiências anteriores com propriedades das situações problema as quais os chimpanzés expostos.

Epstein et al. (1984) desenvolveram uma situação problema para pombos análoga ao teste de empilhamento de caixas de Köhler (1916/1948), na qual uma banana de plástico (escolhida propositalmente, em referência ao trabalho de Köhler) ficava pendurada no teto da caixa, e afastado do local da banana, havia uma caixa. A solução do problema requeria portanto: (1) empurrar a caixa em direção à banana, (2) parar de empurrar a caixa assim que ela estivesse próxima ou abaixo da banana, (3) subir na caixa e (4) bicar a banana. Entretanto, Epstein et al. (1984) não treinaram esses repertórios de forma encadeada, mas sim de maneira independente.

Os autores elencaram dois repertórios pré-requisito para a tarefa planejada: (a) empurrar a caixa em direção a um alvo verde, feito de papelão, afixado em locais aleatórios da parede da câmara experimental, e (b) subir na caixa, presa ao chão, localizada abaixo da banana, e bicar a banana (Figura 3). Adicionalmente, todos os animais foram expostos à sessões de extinção de respostas de "força bruta", que nada mais eram do que respostas de voar em direção à banana. No teste, animais que aprenderam os dois repertórios pré-requisito resolveram a tarefa de forma fluída e súbita, de forma similar aos chimpanzés proficientes de Köhler. Entretanto, animais que aprenderam somente um 
dos dois repertórios, ou tiveram o treino incompleto de empurrar (aprenderam a empurrar de forma não-direcionada) não resolveram a tarefa, ou resolveram de forma errática, e em muito mais tempo. Diante disso, Epstein et al. (1984) argumentam que foi possível criar uma história operante que levou a uma performance típica de "Insight" em uma situação problema. Em tese entao, para se obter esse resultado, basta decompor o problema em questão em seus pré-requisitos e treina-los, mesmo que de forma independente um dos outros (i.e. não encadeados). Sem esses pré-requisitos, a solução, o "Insight" não ocorre.

Um ano após a publicação do estudo original de "Insight" em pombos, Epstein (1985b) publicou um estudo no qual três repertórios distintos foram treinados de forma independente, e dá o nome de recombinação de repertórios ao processo responsável pela integração destes comportamentos aprendidos isoladamente. Posteriormente, Epstein (1987) publicou mais um estudo, desta vez com uma situação problema que envolvia a recombinação de quatro repertórios, e utilizou estes dados pra formular sua teoria generativa do comportamento (Epstein, 2015a). Shettleworth (2012), ao fazer uma revisão dos estudos sobre "Insight" em animais não humanos, aponta que os dois principais trabalhos sobre o tema no século XX são: o trabalho pioneiro de Köhler (1917/1948) e a série de artigos de "Insight" em pombos (Epstein et al. 1984; Epstein, 1985b; 1987).

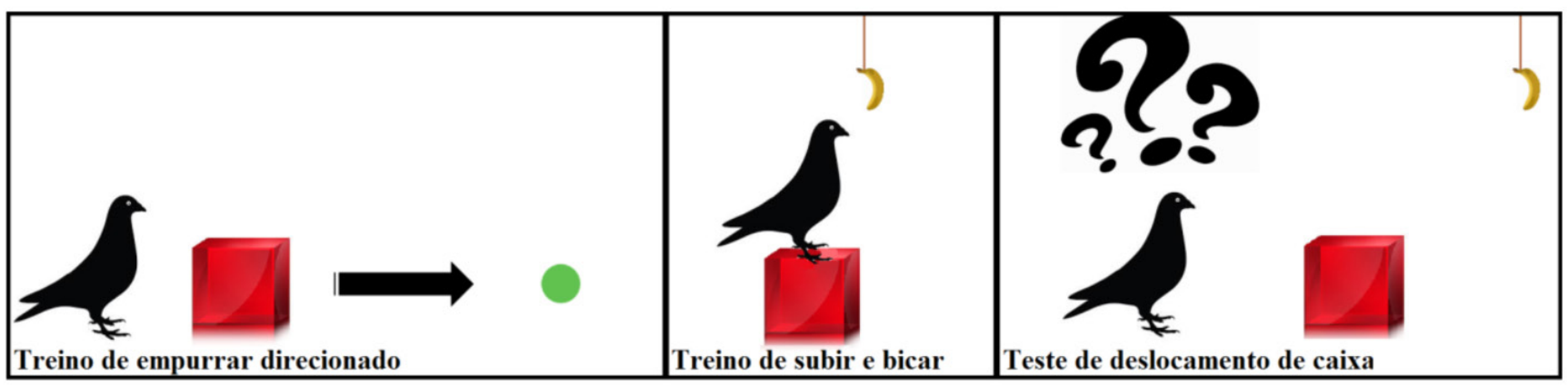

Figura 3. Diagrama esquemático das situações de treino e teste do experimento de Epstein, Kirshnit, Lanza e Rubin (1984). No treino de empurrar direcionado (porção esquerda da figura), os pombos aprenderam a gradualmente empurrar com bicadas uma caixa em direção a um alvo verde (feito de papelão), afixado em diferentes locais da parede da câmara experimental. No treino de subir e bicar, a caixa ficava afixada no chão e logo acima dela havia uma banana (porção central da figura). No teste de deslocamento de caixa (porção direita da figura) a caixa estava afastada do alvo, e para solucionar a tarefa, o pombo deveria então empurrar a caixa em direção ao alvo, parar de empurrar assim que a caixa estivesse próxima a este alvo, subir e bicar o alvo; sequência de comportamentos nunca diretamente treinada.

\section{Imitação em pombos}

A imitação há muito é um processo de destaque na literatura, em especial a imitação humana (Bandura, Ross \& Ross, 1963). Entretanto, com animais não humanos, diversos estudos pioneiros não obtiveram dados claros e inequívocos quanto a observação de imitação entre coespecíficos de diferentes espécies (Köhler, 1916/1948; Thorndike, 1911), e o próprio Skinner (1953, p.120) chegou a suspeitar que pombos seriam incapazes de imitar "naturalmente" (i.e. sem um longo treino operante) seus coespecíficos. Entretanto, diversos estudos de etologia e Psicologia Comparada começaram a en- contrar evidências de imitação espontânea imediata (na presença do modelo) e atrasada (sem a presença do modelo) em diferentes pássaros (Alcock, 1969). O próprio Skinner (1962), anos depois de ter levantado sua suspeita inicial sobre a incapacidade imitativa de pombos, encontrou evidências deste fenômeno em alguns de seus experimentos didáticos com a espécie. Nesse contexto, Epstein (1984), em seu último artigo relacionado ao projeto, testou e demonstrou a imitação espontânea em pombos.

Epstein (1984) descreve três experimentos. A câmara experimental consistia em uma caixa aco- 
plada, separada ao meio por uma parede translúcida, que continha um par de operandos idênticos, um de cada lado da câmara, alinhados horizontalmente (Figura 4). Diferentes pares de pombos interagiam com diferentes pares de operandos, que podiam ser uma bola de ping pong afixada à parede da câmara, uma argola de plástico, ou um disco inserido em um recesso. O procedimento geral consistia em treinar um pombo no papel de modelo, e permitir que outros pombos experimentalmente ingênuos observassem o pombo modelo bicando os operandos.

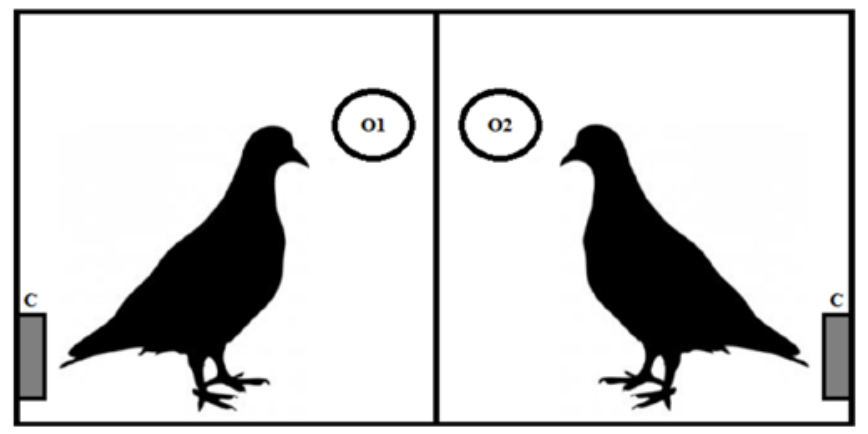

Figura 4. Desenho esquemático do procedimento utilizado por Epstein (1984) para estudar imitação em pombos. Os pombos modelos sempre foram colocados no lado esquerdo da câmara acoplada (porção esquerda da foto). Em ambos os lados da câmara, havia dois operandos idênticos (O1 e O2), que podiam ser uma bola de ping pong, uma argola ou um disco afixado em um recesso na parede. Cada lado da câmara possuía um comedouro $(\mathrm{C})$, entretanto, o comedouro do lado direito da câmara, onde ficavam pombos observadores nunca foi acionado durante os experimentos.

No primeiro experimento, os pombos ingênuos foram inicialmente colocados na porção esquerda da caixa, com os operandos disponíveis e sem a presença do pombo modelo. Nessa etapa, foram medidas as respostas destes pombos direcionadas aos operandos (linha de base). Em uma etapa seguinte, o pombo modelo, com história de treino com os operandos, foi colocado na porção direita da caixa, e na porção esquerda da caixa foi colocado o pombo ingênuo, só que sem a disponibilidade dos operandos. Nas duas etapas seguintes, as etapas de teste, primeiro foi disponibilizados os operandos para o pombo ingênuo ao mesmo tempo em que o pombo modelo tinha também acesso a estes na sua porção da câmara (situação de imitação imediata), e depois apenas o pombo ingênuo foi colocado na caixa, sem o pombo modelo (situação de imitação com atraso) na porção esquerda. Todos os pombos ingênuos tiveram um aumento na frequência de respostas direcionada ao operando que o pombo modelo interagia. Não havia nenhuma consequência aos pombos ingênuos que interagiam com os operandos, enquanto que os pombos modelo recebiam alimento ao interagir com os operandos.

O segundo experimento descrito é idêntico ao primeiro experimento, entretanto foi suprimida a etapa de imitação imediata, e novamente, os pombos desse experimento apresentaram uma maior frequência de respostas no operando manipulado pelo pombo modelo, mesmo só tendo acesso a este após a observação do pombo modelo (imitação com atraso). No terceiro experimento, o pombo modelo foi treinado e consequenciado a dar voltas na caixa, e portanto, não interagiu com os operandos quando serviu de modelo aos pombos ingênuos. Neste experimento, o número de respostas dos pombos ingênuos direcionadas aos operandos foi menor do que nos experimentos nos quais o pombo modelo interagia com estes, o que indica que os pombos ingênuos que interagiram com os operandos nos experimentos anteriores o fizeram em alguma medida sob controle do comportamento do pombo modelo.

\section{Pesquisas não publicadas em artigos isolados}

No seu artigo em que são descritos os objetivos e metas do projeto, Epstein (1981) descreve brevemente dois experimentos que nunca foram publicados em completo em artigos posteriores. Foram estes: um experimento sobre cooperação e "learned helpfulness" e um outro experimento sobre competição. Posteriormente, estes dois experimentos foram também brevemente citados na obra que compila todos os trabalhos do Columban Simulation Project (Epstein, 1996). Desta forma, a descrição a seguir é baseada no que é fornecido pelo autor (Epstein, 1981; 1996), e serve apenas como exemplo dos objetivos do projeto, que tipos de fenômeno eram alvo deste, e como é possível desenhar experimentos de viés operante que tratem de temas pouco tradicionais na Análise do Comportamento. 
Sobre o experimento de cooperação com pombos, Epstein (1981, p.48) apenas comenta “... um [experimento] que chamamos de 'learned helpfulness in pigeons' pode servir como uma conveniente plataforma para discutir a abordagem de Kohlberg com relação à moral" (tradução livre). Kohlberg (1969) desenvolveu uma teoria do desenvolvimento moral humano, pautado em uma visão piagetiana de desenvolvimento. Além disso, o termo "learned helpfulness" parece fazer uma alusão contrastante ao fenômeno de "learned helplessness", o desamparo aprendido (Maier \& Seligman, 1969).

Quanto ao experimento de competição com pombos, Epstein (1981) oferece mais informações, e uma descrição detalhada do procedimento. O procedimento foi desenhado em torno de uma pergunta especulativa: diferentes esquemas de reforço seriam responsáveis por características humanas como um sujeito "mimado" e outro "perseverante"? Epstein (1981) aponta que estudar isso diretamente em humanos envolveria muitas variáveis estranhas com relação à motivação dos participantes, algo que pombos de laboratório não apresentariam. Assim, Epstein (1981) descreve um procedimento no qual dois pombos receberiam um longo treino em diferentes esquemas de razão cada. O pombo "mimado" receberia o treino de bicar o disco em um esquema de reforço contínuo, ou próximo disso, enquanto que o pombo "perseverante" receberia um treino em um esquema de razão mediano. No teste, estes pombos seriam então expostos a uma situação de competição.
No teste, cada pombo seria colocado em uma câmara experimental, cada uma com um disco que poderia ser bicado. Entre as câmaras, haveria um recipiente contendo alimento sob uma esteira. Bicadas no disco da câmara à direita ativariam a esteira de modo a aproximar o recipiente da câmara direita, e bicadas no disco da câmara esquerda aproximariam o recipiente da câmara esquerda (Figura 5). Ambos discos estariam em um esquema de reforço contínuo com relação ao movimento do recipiente na esteira, que seria idêntico em deslocamento para cada disco, mudando somente sua direção. Epstein (1981) então especula que neste cenário, e dado o treino de cada pombo em um esquema distinto, o pombo "mimado" perderia na situação de teste, na medida em que o pombo treinado em um esquema de razão mais exigente emitiria mais respostas, e portanto alcançaria o recipiente com alimento primeiro. Da mesma maneira, pombos com a mesma história de reforço, ou com histórias similares, tenderiam a apresentar uma disputa mais acirrada.

Como nenhum destes dois experimentos teve dados completos publicados, e as informações dadas por Epstein $(1981 ; 1996)$ sobre estes são vagas e incompletas, sua exequibilidade e pertinência estão ainda abertas a um escrutínio empírico. De qualquer forma, ambos experimentos possuem todas as características que os demais experimentos realizados no projeto possuem, como o diálogo com outras áreas de pesquisa, e a demonstração empírica de manipulações operantes de fenômenos complexos.

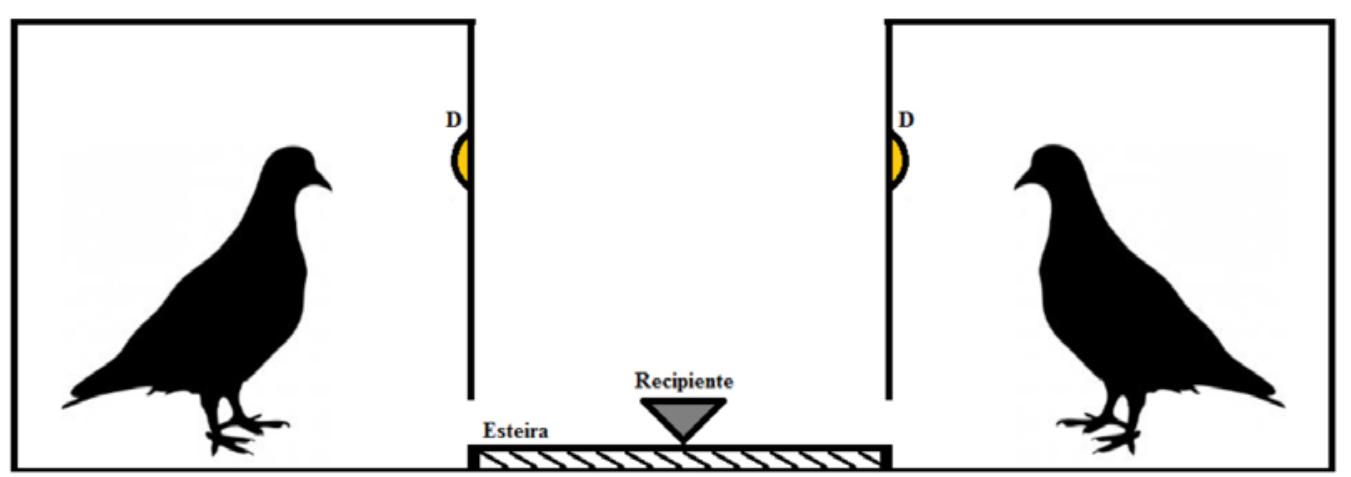

Figura 5. Diagrama esquemático do experimento de competição entre pombos, de acordo com a descrição e fotos de Epstein (1981). Cada câmara experimental possui um disco que se bicado aciona a esteira localizada entre as câmaras. Cada bicada no disco, aciona a esteira na direção deste disco respectivamente, de modo que bicadas no disco da esquerda deslocam a esteira para a esquerda, e bicadas no disco da direita deslocam o disco em direção à direita. Sobre a esteira há um recipiente contendo alimento. O pombo que bicar mais rápido ganha acesso ao recipiente. 


\section{Algumas críticas e legados do projeto}

Dentre as críticas, não há nenhuma pertinente ao projeto como um todo, ao menos até onde o autor conhece da literatura. Entretanto, diversas críticas foram publicadas com relação aos estudos individuais. Dentre estas, uma das mais explícitas é a de Franz de Waal, primatologista que em seu conhecido livro de divulgação científica "The ape and the sushi master" escreveu que o trabalho de auto reconhecimento em pombos de Epstein, Lanza e Skinner, (1981) é uma das "maiores bizarrices da ciência comportamental" (de Waal, 2001, p. 60, tradução livre). O autor oferece está forte crítica sem entrar em detalhes do porque esse seria o caso, e comenta somente que o fenômeno observado por Epstein, Lanza e Skinner (1981) não havia sido devidamente replicado. Entretanto, recentemente Uchino e Watanabe (2014) fizeram exatamente isto.

Uma outra crítica, talvez mais relevante, foi feita ao trabalho de "Insight". Nesta crítica, Ettlinger (1984) levanta a suspeita de que talvez o desempenho de resolução súbita dos pombos se deu somente pois estes estavam em um ambiente que não permitia outras respostas que não fossem as que levassem à solução do problema. Assim, devido ao fato do processo da recombinação de repertórios, como proposto por Epstein (1985b), se pautar somente em um exemplo com pombos, em uma única tarefa específica, este processo era um forte candidato a ser um artefato metodológico. Hoje em dia entretanto tal crítica foi superada, na medida em que a recombinação de repertórios já foi observada em diferentes animais, como ratos, macacos prego, corvos da Nova Caledônia e humanos, em diferentes tarefas (para uma revisão da área, cf. Neves Filho, 2016).

Os trabalhos com os pombos Jack e Jill tiveram dois estudos subsequentes de destaque. O primeiro (Lubinski e MacCorquodale, 1984) observou com outros dois pombos o mesmo desempenho de comunicação simbólica observado no estudo original (Epstein, Lanza \& Skinner, 1980), entretanto, tal performance foi obtida sem um procedimento de privação alimentar ou hídrica dos ani- mais (tal privação seria, segundo os autores, um histórico com estimulação aversiva), e sem uso de reforçadores incondicionados (foram utilizados portanto somente reforçadores condicionados). Lubinski e MacCorquodale (1984) afirmam então que seu procedimento seria análogo a um episódio de comportamento verbal, e não somente um caso de controle de estímulos, como nos estudos originais, que utilizavam de privação e reforços incondicionados. Nesse sentido, os autores então argumentam que seus pombos assumem o papel de um pombo que emite um mando, e outro que emite um tato (o que substituiria o papel original de observador e informante).

O segundo estudo é curiosamente uma simulação em computador do procedimento de Jack e Jill, com um programa (SIMINTERACT II) que simulava uma inteligência artificial adaptativa, que no presente caso foi chamada adequadamente de Columba livia simulata (Muir, 1995a, 1995b). O autor (Muir, 1995a) relata que seu programa foi capaz de aprender as mesmas relações de observador e informante, e partindo disso teve performance idêntica às de Jack e Jill. Muir (1995a, 1995b) argumenta que a operacionalização oferecida pelo estudo com pombos (Epstein, Lanza \& Skinner, 1980) fornece mais informações relevantes para o desenvolvimento de uma simulação em computador, se comparado com o estudo original com chimpanzés (Savage-Rumbaugh, Rumbaugh \& Boysen, 1978), que possuía variáveis de treino e descrição de consequências menos detalhadas. Além disso, o autor (Muir, 1995a; 1995b) argumenta também que sua simulação trás novas maneiras de se entender como são desenvolvidas relações simbólicas simples, partindo de processos adaptativos simulados em computador. Assim, um trabalho com objetivo original de simular um comportamento complexo de chimpanzés em pombos, partindo de um argumento geral de que simulações com animais são, em alguns casos, mais vantajosas que simulações de computador, acabou por dar subsídios para a criação de uma simulação em computador mais precisa e eficiente sobre o fenômeno em questão. Um legado inusitado para um projeto controverso. 


\section{Conclusão}

O Columban Simulation Project não foi o primeiro grande projeto envolvendo Skinner e pombos. Antes disso, durante a segunda guerra mundial, Skinner se dedicou ao ainda mais pitoresco Project Pigeon, (também conhecido como Project ORCON, sigla de Organic Control, ou controle orgânico), que tinha como um de seus objetivos treinar pombos a guiar mísseis balísticos (Skinner, 1960). Deste projeto mais antigo, o principal legado foi a descoberta feita por Skinner do processo de modelagem (Peterson, 2004). Já os legados do Columban Simulation Project foram mais difusos e ainda não tão claros.

De todos os experimentos do Columban Simulation Project, apenas o experimento sobre "Insight" gerou uma linha de pesquisa que continua ativa, produzindo tanto dados sobre as variáveis que alteram a resolução de problemas em uma perspectiva operante, como também um modelo animal para entendimento de causalidade e evolução convergente da criatividade (Neves Filho, 2016; 2018). Os demais experimentos, apesar de terem tido alguns estudos subsequentes, não geraram linhas de investigação mais abrangentes e interdisciplinares.

Uma nota final deve ser realizada quanto a validade da crítica de Epstein (1981) com relação à simulações de computador. É importante ressaltar que o projeto critica e levanta problemas de programas e simulações do século passado. Hoje em dia, com um maior poder computacional disponível, simulações de computador adquiriram um patamar de refinamento muito além do que era possível à época da publicação de Epstein (1981). O próprio Epstein, anos depois, dedicou-se ao desenvolvimento e refinamento de simulações computacionais (Epstein, 2015a) e inteligências artificiais (Epstein, Roberts \& Beber, 2009). De fato, hoje existe toda uma abordagem de inteligência artificial pautada em preceitos operantes (Sutton \& Barto, 1998). Assim, é possível afirmar que hoje, simulações de computador e Análise do Comportamento são disciplinas complementares, e não mais suspeitas uma da outra, como sugerido inicialmente por Epstein (1981).
No que tange uma interface com as ciências cognitivas modernas, cabe comentar que a metáfora do computador tem perdido fôlego (Cromwell \& Panksepp, 2011; Teixeira, 2008), e propostas como a cognição corporeada (Chemero, 2009) tem ganhado destaque recente. Propostas desse tipo tem tirado a cognição da esfera do processamento de informação, e tem tratado fenômenos cognitivos como fenômenos típicos de organismos biológicos, que respeitam suas histórias filogenéticas. Tais propostas cognitivas tem total aproximação com a sugestão de Epstein (1981) de se estudar tais processos em animais, e não em máquinas. Além disso, o uso de procedimentos de recombinação de repertórios por pesquisadores interessados em aspectos como o entendimento de causalidade (e.g.. Cook \& Fowler, 2014; Taylor, Elliffe, Hunt \& Gray, 2010) trazem novas oportunidades de diálogo da Análise do Comportamento com as ciências cognitivas, algo que o Columban Simulation Project almejava.

Assim, apesar da crítica sobre o uso de simulações no estudo do comportamento que permeou todo o projeto hoje ser anacrônica, tal crítica foi o que, em alguma medida, levou a uma maior aproximação das ciências da computação com a Análise do Comportamento, como demonstrado pelos trabalhos de Muir (1995a, 1995b) e o surgimento de uma abordagem de inteligências artificiais pautadas em princípios operantes (Sutton \& Barto, 1998). Entretanto, tal aproximação ainda é complementar, e de maneira alguma elimina o principal apelo do projeto, que é: todo comportamento de um organismo vivo, seja ele rotulado como complexo ou não, possui uma história que o controla, e conhecer essa história, mesmo que a partir de simulações em outras espécies, é um passo em direção à previsão e controle.

\section{Referências}

Alcock, J. (1969). Observational learning in three species of birds. Ibis, 111, 308-321. doi: 10.1111/j.1474-919X.1969.tb02547.x

Bandura, A., Ross, D. \& Ross, S. A. (1963). Imitation of film-mediated agressive models. Journal of Abnormal and Social Psychology, 66, 3-11. doi: $10.1037 / \mathrm{h} 0048687$ 
Baxley, N. (Produtor). (1982). Cognition, creativity, and behavior: The Columban simulations [Vídeo documentário]. Champaign: Research Press. Recuperado em 16 de agosto de 2017 de https://youtu.be/QKSvu3mj-14

Chang, L., Zhang, S., Poo, M. \& Gong, N. (2017). Spontaneous expression of mirror self-recognition in monkeys after learning precise visual-proprioceptive association for mirror images. PNAS, 114, 3258-3263. doi: 10.1073/ pnas.1620764114

Chemero, A. (2009). Radical embodied cognitive science. Cambridge: The MIT Press.

Cromwell, H. C., \& Panksepp, J. (2011). Rethinking the cognitive revolution from a neural perspective: How overuse/misuse of the term 'cognition' and the neglect of affective controls in behavioral neuroscience could be delaying progress in understanding the Brain/Mind. Neuroscience \& Biobehavioral Reviews, 35(9), 2026-2035. doi: 10.1016/j.neubiorev.2011.02.008

de Waal, F. (2001). The Ape and the sushi master. New York: Basic Books.

Epstein, R. (1981). On pigeons and people: A preliminary look at the Columban Simulation Project. The Behavior Analyst, 4, 43-55. doi:10.1007/BF03391851

Epstein, R. (1984). Spontaneous and deferred imitation in the pigeon. Behavioural Processes, 9, 346-354. doi: 10.1016/0376-6357(84)90021-4

Epstein, R. (1985a). The spontaneous interconnection of three repertoires of behavior in a pigeon (Columba livia). Psychological Record, 35, 131141. doi:10.1037/0735-7036.101.2.197

Epstein, R. (1985b). On the Columban simulations: A reply to Gallup. Contemporary Psychology, 30, 417-418. doi: 10.1037/023816. doi: $10.1037 / 023816$

Epstein, R (1985c). Extinction-induced resurgence: Preliminary investigations and possible implications. Psychological Record, 35, 143-153. doi: 10.1007/BF03394918

Epstein, R. (1986). Simulation research in the analysis of behavior. Em A. Poling \& R. W. Fuqua (Eds.). Research methods in applied behavior analysis. New York: Springer.

Epstein, R. (1987). The spontaneous interconnection of four repertoires of behavior in a pige- on (Columba livia). Journal of Comparative Psychology, 101, 197-201. doi: 10.1037/07357036.101.2.197

Epstein, R. (1996). Cognition, creativity and behavior: Selected essays. Westport: Praeger/ Greenwood Publishers.

Epstein, R. (2015a). Of course animals are creative: Insights from generativity theory. Em A. B. Kaufman, \& J.C. Kaufman (Eds.). Animal creativity and innovation. London: Academic Press. Epstein, R. (2015b). On the rediscovery of the principle of resurgence. Mexican Journal of Behavior Analysis, 31, 19-43.

Epstein, R., Lanza, R. P., \& Skinner, B. F. (1980). Symbolic communication between two pigeons (Columba livia domestica). Science, 207, 543545. doi: 10.1126/science.207.4430.543

Epstein, R., \& Skinner, B. F. (1981). The spontaneous use of memoranda by pigeons. Behaviour Analysis Letters, 1, 241-246.

Epstein, R., Lanza, R. \& Skinner, B. F. (1981). “Selfawareness" in the pigeon. Science, 212, 695. doi: 10.1126/science.212.4495.695

Epstein, R. \& Medalie, S. (1983). The spontaneous use of a tool by a pigeon. Behaviour Analysis Letters, 3, 241-247.

Epstein, R., Kirshnit, C. E., Lanza, R. P. \& Rubin, L. C. (1984). "Insight" in the pigeon: Antecedents and determinants of an intelligent performance. Nature, 308, 61-62. doi: 10.1038/308061a0

Epstein, R., Roberts, G. \& Beber, G. (2009). Parsing the Turing Test. New York: Springer.

Ettlinger, G. (1984). Humans, apes and monkeys: the changing neuropsychological viewpoint. Neuropsychologia, 22, 685-696.

Gallup, G. G. (1970). Chimpanzees: Selfrecognition. Science, 167, 86-87. doi: 10.1126/ science.167.3914.86

Galvão, O. F., Soares Filho, P. S. D., Neves Filho, H. B. \& Nagahama, M. M. (2009). Discrimination of complex visual stimuli in Cebus apella: identity matching with pictures. Psychology \& Neuroscience, 2, 35-42. doi: 10.3922/j. psns.2009.1.06

Huttunen, A. W., Adams, G. K. \& Platt, M. L. (2017). Can self-awareness be taught? Monkeys pass the mirror test-again. PNAS, doi: 10.1073/ pnas. 1701676114 
Kohlberg, L. (1964). Development of moral character and moral ideology. Em M. L. Hoffman \& L. W. Hoffman (Eds.). Review of Child Development Research Volume 1. New York: Russel Sage Foundation.

Köhler, W. (1948). The mentality of the apes. New York: New Haven. (Originalmente publicado em alemão em 1916).

Lubinski, D. \& MacCorquodale, K. (1984). "Symbolic communication" between two pigeons (Columba livia) without unconditioned reinforcement. Journal of Comparative Psychology, 98, 372-380. doi: 10.1037/07357036.98.4.372

Maier, S. F. \& Seligman, M. E. P. (1976). Learned helplessness: Theory and evidence. Journal of Experimental Psychology: General, 105, 3-46. doi: 10.1037/0096-3445.105.1.3

Muir, D. E. (1995a). Symbolic communication between two simulated pigeons (Columba livia simulata). Perceptual and Motor Skills, 81, 20-22. doi: 10.2466/pms.1995.81.1.20

Muir, D. E. (1995b). SIMINTERACT II: An enhanced computer program for simulating adaptive systems. Social Science Computer Review, 13, 524-530. doi: 10.1177/089443939501300407

Neves Filho, H. B. (2016). Recombinação de repertórios: Criatividade e a integração de aprendizagens isoladas. Em P. G. Guerra, J. H. Almeida \& C. R. X. Cançado (Orgs.). Experimentos clássicos em Análise do Comportamento Volume 1. Brasília: Editora Walden 4.

Neves Filho, H. B. (2018). Criatividade: Suas origens e produtos sob uma perspectiva operante. Fortaleza: Imagine Publicações.

Peterson, G. B. (2004). A day of great illumination: B. F. Skinner's discovery of shaping. Journal of the Experimental Analysis of Behavior, 82, 317328. doi: 10.1901/jeab.2004.82-317

Savage-Rumbaugh, E. S., Rumbaugh, D. M. \& Boysen, S. (1978). Symbolic communication between two chimpanzees (Pan troglodytes). Science, 201, 641-644. doi: 10.1126/science. 675251

Skinner, B. F. (1953). Science and human behavior. New York: MacMillan.

Skinner, B. F. (1960). Pigeons in a pelican. American Psychologist, 15, 28-37. doi: 10.1037/h0045345
Skinner, B. F. (1962). Two "synthetic social relations". Journal of the Experimental Analysis of Behavior, 5, 531-533. 10.1901/jeab.1962.5-531

Shettleworth, S. J. (2012). Do animals have insight, and what is insight anyway? Canadian Journal of Experimental Psychology, 66(4), 217-266. doi:10.1037/a0030674

Sutton, R. S. \& Barto, A. G. (1998). Reinforcement learning: An introduction. New York: Bradford Book.

Taylor, A. H., Elliffe, D., Hunt, G. \& Gray R. D (2010). Complex cognition and behavioural innovation in new caledonian crows. Proceedings of the Royal Society B, 277, 26372643. doi:10.1098/rspb.2010.0285

Teixeira, J. F. (2008). Mente, cérebro e cognição $3^{a}$ edição. Rio de Janeiro: Vozes.

Thorndike, E. L. (1911). Animal intelligence: Experimental studies. New York: The Macmillan Company.

Uchino, E. \& Watanabe, S. (2014). Self-recognition in pigeons revisited. Journal of the Experimental Analysis of Behavior, 102, 327-334. doi: 10.1002/ jeab.112

\section{Informações do Artigo}

Histórico do artigo:

Submetido em: 25/08/2017

Primeira decisão editorial: 20/08/2018

Aceito em: 29/08/2018

Editor associado: Saulo Velasco 